\title{
Evaluating the Performance of a EuroDivisia Index Using Artificial Intelligence Techniques
}

\author{
Jane M. Binner ${ }^{1, *} \quad$ Alicia M. Gazely ${ }^{2} \quad$ Graham Kendall $^{3}$ \\ ${ }^{1}$ Economics and Strategy Group, Aston Business School, Aston University, Aston Triangle, Birmingham B4 7ET, UK \\ 2 Nottingham Business School, Nottingham Trent University, Burton Street, Nottingham NG1 4BU, UK \\ ${ }^{3}$ School of Computer Science \& IT, University of Nottingham, Jubilee Campus, Wollaton Road, Nottingham NG8 1BB, UK
}

\begin{abstract}
This paper compares two methods to predict inflation rates in Europe. One method uses a standard back propagation neural network and the other uses an evolutionary approach, where the network weights and the network architecture are evolved. Results indicate that back propagation produces superior results. However, the evolving network still produces reasonable results with the advantage that the experimental set-up is minimal. Also of interest is the fact that the Divisia measure of money is superior as a predictive tool over simple sum.
\end{abstract}

Keywords: EuroDivisia, Divisia money, inflation, evolutionary strategies, neural networks.

\section{Introduction}

The novelty of this paper lies in the use of evolved neural networks utilising evolutionary strategies to examine the Euro area's recent experience of inflation. This approach is a unique tool in the context of predicting inflation, and its use is highly exploratory although results presented here give us confidence to believe that significant advances in macroeconomic forecasting and policymaking are possible using techniques such as this. This is the first attempt to evaluate the empirical performance of a EuroDivisia index number measure of money using such an approach. As in our earlier work in [1], results achieved using evolutionary strategies are compared with those using traditional trained neural networks.

The objective of the current monetary policy is to identify indicators of macroeconomic conditions that will alert policy makers to impending inflationary pressures sufficiently early to allow the necessary action to be taken to control and remedy the problem. It is widely accepted that the maintenance of a low rate of inflation provides the stable macroeconomic environment necessary to promote sustained economic growth and rising living standards. In addition, accurate forecasting encourages those contemplating investments and long-term projects, while uncertainty discourages speculation and growth.

Monetary policy in the Euro area is carried out under the so-called two pillars. First, given the widely held belief that development in the price level is a monetary phenomenon, development in the amount of money held by the public may reveal useful information about future price development and be a useful leading indicator of inflation. Therefore, in its first pillar, the European central bank (ECB) has given broad monetary aggregate M3 a prominent role for guiding monetary policy.

Manuscript received May 1, 2007; revised October 30, 2007 *Corresponding author. E-mail address: j.m.binner@aston.ac.uk
The "two pillared" approach used by the European Central Bank ${ }^{[2]}$, specifically states that " ... the president's introductory statement will (after identifying short to medium-term risks to price stability) proceed to monetary analysis to assess medium to long-term trends in inflation in view of the close relationship between money and prices over extended horizons." Hence the importance of this current research.

Given that M3 is constructed by simple summation, its use as a macroeconomic policy tool is highly questionable. More specifically, this form of aggregation weighs equally and linearly assets as different as cash and bonds. This form of aggregation involves the explicit assumption that the excluded financial assets provide no monetary services and the included balances provide equal levels of monetary services, whether they are cash or "checkable" deposits or liquid savings account balances. It is clear that all components of the monetary aggregates do not contribute equally to the economy's monetary services flow. Obviously, one hundred Euros currency provides greater transactions services than the equivalent value in bonds. Thus, this form of aggregation is therefore producing a theoretically unsatisfactory definition of the economy's monetary flow. The second ECB pillar analyzes a broad range of other economic and financial indicators relevant to future price development ${ }^{[2]}$.

In the last two decades, many countries have relegated the role of monetary aggregates from macroeconomic policy control tool to indicator variables. Barnett ${ }^{[3,4]}$ attributed to a great extent the downgrading of monetary aggregates to the use of simple sum aggregates as they have been unable to cope with financial innovation. By drawing on statistical index number theory and consumer demand theory, Barnett advocates the use of chain-linked index numbers as a means of constructing a weighted Divisia index number measure of money. The potential advantage of the Divisia monetary aggregate is that the weights can vary over time in response to financial innovation. Reference [5] provided a survey of 
the relevant literature, whilst [6] reviewed the construction of Divisia indices and associated problems.

\section{$2 \quad$ Data and forecasting model}

In this study, the performance of a EuroDivisia monetary index is compared with that of the Euro simple sum index. Many economic indicators help predict inflation. For example, the literature [7] has shown that 168 variables can be used to forecast US inflation. In our study, instead of using so many variables, we limit the list to those that are more closely linked to inflation by economic theory or that have been regularly used in previous empirical studies. Thus, in keeping with our earlier work in [1], the variables required for multivariate forecasting are: inflation, monetary aggregates Euro M3 (SM3) and Euro Divisia M3 (DM3), short and long run interest rates and the opportunity cost variables of the corresponding simple sum and Divisia aggregates. These are quarterly seasonally adjusted data for the period 1980Q1 to 2000Q4, defined by the availability of the Euro area data. All data on monetary assets and their respective rates of return have been obtained from [8]. Inflation was constructed for each quarter as year-on-year growth rates of prices.

With respect to market interest rates, we consider a weighted average of 3-month money market interest rates and of 10 year government bond yields as representative of, respectively, short-term and long term market rates in the Euro area. These latter have also been taken directly from [8]. After allowing for lags, estimation is conducted using data from 1981Q2 to 1999Q1, while the remaining 7 observations (1999Q2 to 2000Q4) are kept for forecast evaluation (testing). Euro M3 is constructed by simply summing over the monetary components while the Divisia index is constructed using equation (9) in [5, pp. 2097]. The more usual form of the index is the log change form as follows:

$$
\ln M_{t}-\ln M_{t-1}=\sum_{i=1}^{n} s_{i t}^{*}\left[\ln m_{i t}-\ln m_{i(t-1)}\right]
$$

where $M_{t}$ denotes the Divisia monetary aggregate at time $t, s_{i t}^{*}$ is the share weight held of each component asset, $m_{i t}$ and $m_{i(t-1)}$ are the average share held of asset $i$ in $t$ and $t-1$, respectively.

We use the Divisia price dual ${ }^{[3]}$ as the opportunity cost variable for Divisia index. Following the work in [9], the opportunity cost variable for the simple sum aggregate is calculated as $\left(R_{t}-r_{t}\right)$ where $R_{t}$ is a long term interest rate and $r_{t}$ is the own rate of Euro M3.

A model of the relationship between money and inflation was employed as the basis for our work that takes inflation in the current quarter to be a function of money measures in the four preceding quarters. The model also includes an autoregressive term, representing inflation for the preceding period.

This simple model is the preferred specification in our earlier neural network studies since it consistently outperforms even simpler model constructs. Simple and constant designs are chosen specifically to allow the information content of the monetary variables to be evaluated on an equal footing, even though it is virtually certain in this context that more accurate inflation forecasting models could be achieved with the inclusion of additional explanatory variables. In the same vein, we recognize that a more complex model design will almost certainly yield superior results. However, this paper focuses on a comparison of evolved neural networks utilizing evolutionary strategies with more traditional neural network techniques and so a simple model is thought to be more appropriate.

The model was tested in five variations, monetary index alone, short interest rate added, long interest rate added, both long and short interest rates added, and interest rate dual added. Interest rates were also lagged for four quarters to be consistent with the monetary indices.

\section{Trained neural network methodology}

Artificial neural networks $\left(\mathrm{ANNs}^{[10-12]}\right.$ consist of simple interacting processing units that are arranged in arbitrary layers with variable patterns of interconnectedness. Knowledge is represented as connection strengths (or weights) between connected units. Each processing unit spreads its activation to the connected units after combining and processing its input using some linear or non-linear activation function. Learning occurs when general recursive rules are applied to adapt these weights to produce desired output responses.

ANNs are becoming increasingly popular in economics and are used in a large variety of modeling and forecasting problems. The main reason for this increased popularity is that these models have been shown to be able to approximate any non-linear function arbitrarily close ${ }^{[13,14]}$. Hence, when applied to a time series which is characterized by truly non-linear dynamic relationships, the ANN will provide a global approximation to this unknown non-linear relationship. Previous studies unveil the applicability of ANNs to modeling and forecasting in economics. Applications to inflation include [1, 7, 15-17].

Standard back-propagation networks ${ }^{[12]}$ were created using the Matlab neural networks toolbox. The transfer functions used were tan-sigmoid for the units in the hidden layer and linear for the output layer. The random seed was reset to a known value for each network to aid replication of the weights initialisation process, and the batch update method was used. Each network was trained for 2000 epochs. The number of hidden units was varied to take values between 1 and 8 inclusive, and the learning rate was also varied to give a range of 5 values between 0.001 and 0.05 . This aimed to form a (relatively) small set of 40 network designs which have a good chance of convergence. Given two monetary indices and five variations of inputs, a total of 400 networks were run.

\section{Evolving neural networks}

Utilizing a back propagation network, as described in the previous section, produces good results as shown in Section 5. However, this approach can be labour intensive as the number of hidden neurons, the activation function, which 
inputs to use and so on must all be considered to arrive at a network that produces the required results. In an attempt to eliminate the need to conduct tests to define the various settings, we have experimented with an evolving network.

We decided to let the neural network evolve, but not only in the weights, which was the focus of our previous work. In this work we also let the structure of the network evolve as well as letting the evolutionary process decide which inputs are most relevant.

Networks using evolutionary strategies are closely related to genetic algorithms. Early evolutionary strategies only used a population of one single individual and only mutation as the mechanism for evolution. More recently, they have used a population size greater than one and crossover as well as mutation. However, for the optimization of real variables, they have been used with mutation rather than crossover. In this study, a larger population with mutation has been employed. The procedure is as follows.

A population of neural networks is instantiated. In this work, the population size is 20 . The number of inputs range between 5 and 17 . The previous quarter's inflation is always input (one input). Also, one of the measures of money (simple sum or Divisia) is also input (four neurons). Initially, the measure of money is selected at random. Optionally, we also input the dual measure (four neurons), short interest (four neurons), and long interest (four neurons).

The population of networks are evaluated and assigned a fitness value, based on how well they predict the out of sample values. The ten worst performing networks are deleted. The ten remaining networks are then copied to maintain a population size of twenty, and then they are mutated in some way. The mutation is drawn at random from the following operators:

Change weights. Change the weights in the network using a Gaussian random number with a mean of zero and a standard deviation of one.

Change measure. Randomly choose between simple sum and Divisia as the measure of money that is input to the network. The dual measure, if used, is also changed if necessary.

Reverse dual. If currently using the dual, then stop using it and vice versa.

Change activation function. Change the activation function by randomly choosing sigmoid or tanh.

Add hidden neuron. Add a neuron to the network hidden layer.
Delete hidden neuron. Delete a neuron from the hidden layer.

Change interest. Randomly decide whether to use long or short interest. Only one of the interest types is considered at any one time. That is, if we decide to consider long interest, we will also not make a change to the status of short interest in this generation.

The above process (evaluate, kill off the worst networks, copy the best ones, and mutate them) was carried out for 20000 generations, and repeated six times.

\section{Results}

Three standard forecasting evaluation measures were used to compare the predicted inflation rate with the actual inflation rate, namely, root mean squared error (RMSE), mean absolute difference (MAD), and mean absolute percent error (MAPE). Tables 1 and 2 show the best six results, using the MAPE criterion, from our two alternative experiments (trained network versus evolved network). The results are divided between in-sample (the training set) and out-of-sample (the validation set).

A comparison of the performance of the two alternative monetary constructs reveals that the Divisia formulation provides superior forecasts in 9 out of the 12 cases examined; DM3 is clearly superior based on the evolutionary strategy results, although the picture is a little less clear cut when the neural network results are considered.

Contrary to expectations, the price dual did not improve on the forecasting performance of the monetary aggregate. It appears that the price dual should be used primarily as a tool to stabilise demand for money functions, as implied by [18], and use of a price dual is certainly worthy of further investigation. Evidence presented here suggests that a short rate of interest adds value, alongside money, in forecasting future inflation in the Euro area.

A comparison of the evolved networks with the traditional trained neural networks reveals that the latter significantly outperform the evolved networks. The out of sample MAPE forecasts are roughly $50 \%$ lower in the case of the trained networks. However, the main advantage of the evolved network is the fact that the weights and network structure are evolved. This reduces the number of experiments that have to be carried out to find a suitable network structure and to determine which inputs are relevant to the problem at hand.

Table 1 Trained neural network results (best 6 results)

\begin{tabular}{|c|c|c|c|c|c|c|c|c|c|}
\hline \multicolumn{3}{|c|}{ Within sample } & \multicolumn{3}{|c|}{ Out of sample } & \multirow{2}{*}{$\begin{array}{c}\text { Input } \\
\text { neurons }\end{array}$} & \multirow{2}{*}{$\begin{array}{l}\text { Hidden } \\
\text { neurons }\end{array}$} & \multirow{2}{*}{$\begin{array}{c}\text { Divisia } \\
\text { type }\end{array}$} & \multirow{2}{*}{$\begin{array}{c}\text { Interest } \\
\text { type }\end{array}$} \\
\hline RMSE & MAD & MAPE & RMSE & MAD & MAPE & & & & \\
\hline 0.002798 & 0.0022 & $6 \%$ & 0.001568 & 0.0009 & $7 \%$ & 9 & 3 & DM3 & DUAL \\
\hline 0.002262 & 0.0017 & $5 \%$ & 0.001292 & 0.0009 & $7 \%$ & 9 & 6 & SM3 & DUAL \\
\hline 0.002743 & 0.0021 & $6 \%$ & 0.001025 & 0.0009 & $7 \%$ & 13 & 8 & SM3 & SHORT \& LONG \\
\hline 0.003100 & 0.0024 & $7 \%$ & 0.001703 & 0.0010 & $7 \%$ & 13 & 6 & SM3 & SHORT \& LONG \\
\hline 0.002739 & 0.0021 & $6 \%$ & 0.001108 & 0.0009 & $7 \%$ & 13 & 8 & DM3 & SHORT \& LONG \\
\hline 0.002834 & 0.0023 & $7 \%$ & 0.001712 & 0.0010 & $8 \%$ & 9 & 3 & DM3 & DUAL \\
\hline
\end{tabular}


Table 2 Evolved neural network results (6 results)

\begin{tabular}{|c|c|c|c|c|c|c|c|c|c|}
\hline \multicolumn{3}{|c|}{ Within sample } & \multicolumn{3}{|c|}{ Out of sample } & \multirow{2}{*}{$\begin{array}{l}\text { Input } \\
\text { neurons }\end{array}$} & \multirow{2}{*}{$\begin{array}{l}\text { Hidden } \\
\text { neurons }\end{array}$} & \multirow{2}{*}{$\begin{array}{l}\text { Divisia } \\
\text { type }\end{array}$} & \multirow{2}{*}{$\begin{array}{c}\text { Interest } \\
\text { type }\end{array}$} \\
\hline RMSE & MAD & MAPE & RMSE & MAD & MAPE & & & & \\
\hline 0.011123 & 0.0083 & $21 \%$ & 0.002721 & 0.0019 & $15 \%$ & 5 & 1 & DM3 & NONE \\
\hline 0.011074 & 0.0083 & $21 \%$ & 0.002672 & 0.0019 & $15 \%$ & 5 & 1 & DM3 & NONE \\
\hline 0.011047 & 0.0080 & $20 \%$ & 0.002589 & 0.0018 & $14 \%$ & 9 & 1 & DM3 & SHORT \\
\hline 0.011039 & 0.0083 & $21 \%$ & 0.002705 & 0.0018 & $14 \%$ & 5 & 1 & DM3 & NONE \\
\hline 0.010822 & 0.0078 & $20 \%$ & 0.002410 & 0.0014 & $11 \%$ & 9 & 1 & DM3 & SHORT \\
\hline 0.010772 & 0.0078 & $20 \%$ & 0.002368 & 0.0014 & $11 \%$ & 9 & 1 & DM3 & SHORT \\
\hline
\end{tabular}

\section{Conclusions}

Artificial Intelligence techniques in general and coevolution in particular are highly effective tools for predicting future movements in inflation. There is tremendous scope for further research into the development of these methods as new macroeconomic forecasting models. The evidence presented here provides overwhelming support for the view that Divisia indices are superior to their simple sum counterparts as macroeconomic indicators. It may be concluded that a money stock mismeasurement problem exists and the role of monetary aggregates in the major economies today has largely been relegated to one of a leading indicator of economic activity, along with a range of other macroeconomic variables.

However, further empirical work on Divisia money and, in particular, close monitoring of Divisia constructs may serve to restore confidence in former well established moneyinflation links. Empirical research has often stressed that both the composition and construction of monetary aggregates matter for gauging their value in empirical settings (see, for examples, [19-22]). Hence, the composition of the monetary aggregate will be the subject of our future research. Ultimately, it is hoped that money may be reestablished as an effective macroeconomic policy tool in its own right using techniques such as those presented here.

As a forecasting tool, non-linear techniques such as standard back-propagation networks and evolving neural networks have proved effective, and the evolved networks promise to allow a semi-automated approach whereby forecasts can be updated in the light of new data as time passes without the labour intensive model selection which is characteristic of the traditional approach.

\section{Acknowledgements}

The authors thank Thomas Elger (Lund University, Sweden) and Barry Jones (State University of New York, US) for their helpful discussions during the development of this paper.

\section{References}

[1] J. M. Binner, G. Kendall, A. M. Gazely. Evolved vs. Trained Neural Networks: An Evaluation of UK Risky Money. In Proceedings of International Conference on Computational Economics and Finance, Global Business and Economics Review, to be published.

[2] European Central Bank. The Outcome of the ECB's Evaluation of Its Monetary Policy Strategy. ECB Monthly Bulletin, pp. 87-102, 2003.

[3] W. A. Barnett. The User Cost of Money. Economic Letters, vol. 1, no. 2, pp. 145-149, 1978. Reprinted in The Theory of Monetary Aggregation, W. A. Barnett, A. Serletis (eds.), North-Holland, Amsterdam, Holand, Chapter 1, pp. 6-10, 2000 .

[4] W. A. Barnett. Economic Monetary Aggregates: An Application of Index Number and Aggregation Theory. Journal of Econometrics, vol. 14, no. 1, pp. 11-48, 1980. Reprinted in The Theory of Monetary Aggregation, W. A. Barnett, A. Serletis (eds.), North-Holland, Amsterdam, Holand, Chapter 2, pp. 11-48, 2000.

[5] W. A. Barnett, D. Fisher, A. Serletis. Consumer Theory and the Demand for Money. Journal of Economic Literature, vol. 30, no. 4, pp. 2086-119, 1992. Reprinted in The Theory of Monetary Aggregation, W. A. Barnett, A. Serletis (eds.), North Holland, Amsterdam, Holand, pp. 389 427,2000 .

[6] L. Drake, A. W. Mullineux, J. Agung. One Divisia Money for Europe. Applied Economics, vol. 29, no. 3, pp. 775-786, 1997.

[7] J. H. Stock, M. W. Watson. Forecasting Inflation. Journal of Monetary Economics, vol. 44, no. 2, pp. 293-335, 1999.

[8] L. Stracca. Does Liquidity Matter? Properties of a Synthetic Divisia Monetary Aggregate in the Euro Area. Oxford Bulletin of Economics and Statistics, vol. 66, no. 3, pp. 309-331, 2004.

[9] H. Lutkepohl, J. Wolters. A Money Demand System for German M3. Empirical Economics, vol. 23, no. 3, pp. 37186, 1998. 
[10] D. E. Rumelhart, G. E. Hinton, R. J. Williams. Learning Internal Representations by Error Propagation. Parallel Distributed Processing, Explorations in the Microstructure of Cognition, MIT Press, Cambridge, MA, USA, vol. 1, pp. 318-362, 1986.

[11] B. Cheng, D. M. Titterington. Neural Networks: A Review from a Statistical Perspective. Statistical Science, vol. 9, no. 1, pp. 2-30, 1994.

[12] S. Haykin. Neural Networks: A Comprehensive Foundation, 2nd edition, Prentice Hall, Upper Saddle River, NJ, USA, 1999.

[13] G. Cybenko. Approximation by Superpositions of a Sigmoidal Function. Mathematics of Control, Signals, and Systems, vol. 2, no. 4, pp. 303-314, 1989.

[14] K. Hornik. Approximation Capabilities of Multilayer Feedforward Networks. Neural Networks, vol. 4, no. 2, pp. 251257, 1991.

[15] S. Moshiri, N. Cameron, D. Scuse. Static, Dynamic and Hybrid ANN Models in Forecasting Inflation. Computational Economics, vol. 14, no. 3, pp. 219-235, 1999.

[16] J. M. Binner, A. M. Gazely, S. H. Chen, B. Chie. Financial Innovation and Divisia money in Taiwan: Comparative Evidence from Neural Network and Vector Error Correction Forecasting Models. Contemporary Economic Policy, vol. 22, no. 2, pp. 213-224, 2004.

[17] J. M. Binner, T. Elger, B. Nilsson, J. Tepper. Tools for Non-linear Time Series Forecasting in Economics: An Empirical Comparison of Regime Switching Vector Autoregressive Models and Recurrent Neural Networks. Advances in Econometrics, vol. 19, pp. 71-92, 2005.

[18] M. T. Belongia. The Neglected Price Dual of Monetary Quantity Aggregates. Money, Measurement and Computation, M. T. Belongia, J. M. Binner (eds.), Palgrave Macmillan, Chapter 10, pp. 239-255, 2005.

[19] J. L. Swofford, G. A. Whitney. The Composition and Construction of Monetary Aggregates. Economic Inquiry, vol. 29, no. 4, pp. 752-761, 1991.

[20] M. T. Belongia. Measurement Matters: Recent Results from Monetary Economics Re-examined. Journal of Political Economy, vol. 104, no. 5, pp. 1065-1083, 1996.

[21] D. L. Schunk. The Relative Forecasting Performance of the Divisia and Simple Sum Monetary Aggregates. Journal of Money, Credit, and Banking, vol. 33, no. 2, pp. 272-283, 2001.

[22] J. V. Duca, D. D. VanHoose. Recent Developments in Understanding the Demand for Money. Journal of Economics and Business, vol. 56, no. 4, pp. 247-272, 2004.

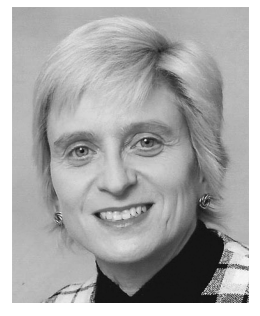

Jane M. Binner applies traditional methods such as investment appraisal analysis and also state of the art modelling methods such as dynamic game theory modelling. Her work centres on the application of advanced multivariate techniques to a range of data types, particularly the econometric and time series analysis of financial data. The work, which is largely multidisciplinary in nature, involves both commercial applications and more academic approaches. She has over fifty refereed publications and three books. She has a successful track record in managing large international multidisciplinary projects.

Her research interests include the application of advanced multivariate techniques to a range of data types, particularly the econometric and time series analysis of macroeconomic and business data.

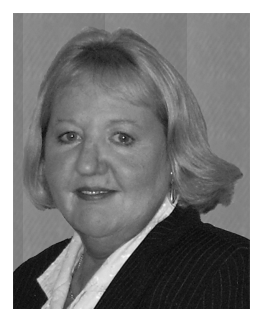

Alicia M. Gazely graduated from the University of Manchester (UK) in 1970. She received the $\mathrm{Ph} . \mathrm{D}$. degree in ergonomics from the University of Loughborough in 1977 and qualified as a chartered accountant in 1979. She is currently a senior lecturer in information systems, Nottingham Business School.

Her research interests include the application of artificial intelligence techniques, specifically, neural networks to economic and business problems.

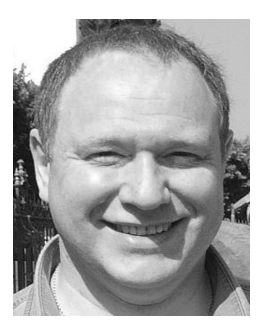

Graham Kendall is a member of the Automated Scheduling, Optimisation and Planning Research Group at the University of Nottingham. He is a member of the UK Engineering and Physical Sciences Research Council (EPSRC) Peer Review College and an associate editor of six international journals. He also chairs the steering committee of the Multidisciplinary International Conference on Scheduling: Theory and Applications (MISTA) and has chaired several other international conferences. He has been a member of the programme (or refereeing) committees of over 70 international conferences over the last few years. During his career, he has edited/authored 10 books and has published over 80 refereed papers. He has been awarded externally funded grants worth over 5M pounds from a variety of sources including EPSRC and commercial organizations.

His research interests include adaptive learning (with an emphasis on game intelligence), heuristic development, optimization, scheduling, and artificial intelligence. 